\title{
PENTINGNYA PENGETAHUAN PERAWAT TENTANG SASARAN KESELAMATAN PASIEN DI RUMAH SAKIT
}

\section{Maranti Syah}

\section{Email: marantisyah555@gmail.com}

\begin{abstract}
ABSTRAK
Latar Belakang: Sasaran keselamatan pasien adalah cerminan dari fasilitas pelayanan di suatu rumah sakit. Keselamatan pasien adalah suatu variabel untuk mengukur dan mengevaluasi terkait dengan kualitas pelayanan keperawatan yang berdampak terhadap pelayanan kesehatan. Pengetahuan tenaga kesehatan dalam sasaran keselamatan pasien terdiri dari yaitu, ketepatan identifikasi pasien, peningkatan komunikasi yang efektif, peningkatan keamanan obat yang perlu diwaspadai kepastian tepat lokasi, tepat prosedur, dan tepat pasien operasi, pengurangan risiko infeksi terkait pelayanan kesehatan, pengurangan risiko pasien jatuh. Perilaku perawat dengan kemampuan perawat sangat berperan penting dalam pelaksanaan keselamatan pasien. . Metode: Metode yang digunakan ialah menggunakan literature review. Hasil: Pengetahuan perawat terkait dengan sasaran keselamatan pasien. Pengetahuan sangatlah penting bagi perawat untuk menerapkan keselamatan pasien di rumah sakit.
\end{abstract}

\section{Kata Kunci: Perawat, Sasaran Keselamatan Pasien, Rumah Sakit.}

\section{LATAR BELAKANG}

Rumah Sakit adalah institusi pelayanan kesehatan yang menyelenggarakan pelayanan kesehatan secara paripurna yang memiliki risiko tinggi terhadap keselamatan pasien, pendamping pasien, pengunjung, maupun sumber daya manusia dan lingkungan rumah sakit, sehingga wajib diselenggarakan keselamatan dan kesehatan agar menghasilkan kondisi rumah sakit yang sehat, aman, selamat dan nyaman secara berkesinambungan (KEMENKES RI, 2016).

Sasaran Keselamatan Pasien (SKP) menjadi parameter standar dasar yang utama dalam penilaian Akreditasi Rumah Sakit (KARS, 2013). Prosedur keselamatan pasien ini sangat menjamin peningkatan mutu dari suatu rumah sakit. Karena suatu rumah sakit dapat dikatakan baik jika pelayanan kesehatan untuk keselamatan pasien juga sudah baik. Dalam hal ini semua pihak di dalam rumah 
sakit saling terlibat satu dengan yang lainnya, mulai dari yayasan pemilik, direksi, para dokter, perawat, dan profesional lainnya serta staf pada umumnya.

Mendirikan pembangunan kesehatan meliputi upaya kesehatan dan sumber dayanya yang harus dilakukan secara terpadu dan berkesinambungan sehingga mencapai suatu tujuan yang optimal untuk menjaga dan meningkatkan mutu pelayanan kesehatan rumah sakit harus mempunyai suatu ukuran atau pedoman yang menjamin peningkatan mutu di semua tingkatan.

Keselamatan pasien menjadi topic terkini karena makin meningkatnya kejadian tidak diharapkan (KTD) atau adverse event. Insiden keselamatan pasien di rumah sakit akan mengakibatkan dampak yang merugikan bagi pihak rumah sakit, para staf dan pasien pada khususnya karena sebagai penerima pelayanan. Dampak yang ditimbulkan ialah berkurangnya tingkat kepercayaan masyarakat terhadap pelayanan kesehatan yang terjadi akibat rendahnya kualitas dan mutu asuhan yang diberikan.

Upaya penerapan keselamatan sangat terkait dengan pengetahuan perawat. Apabila perawat menerapkan keselamatan pasien yang didasari oleh pengetahuan yang memadai, maka perilaku keselamatan pasien oleh perawat tersebut bersifat langgeng (longlasting). Seorang perawat dalam memberikan asuhan keperawatan kepada pasien harus memiliki pengetahuan yang benar, keterampilan, dan sikap untuk menangani kompleksitas perawatan kesehatan.

Tenaga perawat ialah tenaga profesional yang berperan penting dalam fungsi rumah sakit. Hal tersebut berdasarkan dari jumlah tenaga perawat sebagai porsi terbesar didalam pelayanan rumah sakit. Dalam menjalankan perannya, perawat ialah orang yang memiliki kontak terbanyak dengan pasien.

Perawat juga adalah bagian dari suatu tim, yang didalamnya terdapat berbagai profesional lain seperti dokter, apoteker, dll. Luasnya fungsi perawat memungkinkannya terjadinya risiko kesalahan pelayanan. Hal-hal tersebut menempatkan fungsi perawat sebagai komponen penting dalam pelaporan kesalahan pelayanan dalam pengembangan program keselamatan pasien di rumah sakit.

Dalam Permenkes RI No. 1691/ MENKES/ PER/ VIII/ 2011 tentang Keselamatan Pasien Rumah Sakit, dikatakan terkait dengan Insiden keselamatan pasien yang selanjutnya 
disebut insiden ialah setiap kejadian yang tidak disengaja dan kondisi yang mengakibatkan atau berpotensi menimbulkan cidera yang dapat dicegah pada pasien, terdiri dari Kejadian Tidak Diharapkan (KTD), Kejadian Nyaris Cedera (KNC), Kejadian Tidak Cedera (KTC) dan Kejadian Potensial Cedera (KPC).

Sasaran Keselamatan Pasien (SKP) menjadi parameter standar dasar yang utama dalam penilaian Akreditasi Rumah Sakit versi 2012 (KARS, 2013). Ada 6 sasaran keselamatan pasien diantaranya yaitu Ketepatan identifikasi pasien; Peningkatan komunikasi yang efektif; Peningkatan keamanan obat yang perlu diwaspadai; Kepastian tepat lokasi, tepatprosedur, tepat-pasien operasi; Pengurangan risiko infeksi terkait pelayanan kesehatan; dan Pengurangan risiko pasien jatuh (Permenkes Nomor 1691, 2011).

Keselamatan pelayanan di rumah sakit salah satunya dimulai dari ketepatan identifikasi pasien. Karena salah identifikasi pasien yang diidentifikasi sebagai akar penyebab banyak kesalahan yang terjadi (WHO, 2007).

Insiden keselamatan pasien di Indonesia pada tahun 2009 hingga 2011 ialah sebanyak 114, 103, dan 34 laporan secara berturutan. Insiden keselamatan pasien diantaranya yaitu dari Kejadian Tidak Diharapkan (KTD), Kejadian Nyaris Cedera (KNC), Kejadian Tidak Cedera (KTC), dan Kejadian Potensial Cedera (Syurandhari, 2016). Kejadian yang tidak diharapkan dan kesalahan pengobatan dapat terjadinya $3-17 \%$ pasien yang dirawat di rumah sakit mengalami komplikasi. Terdapat 30- 70\% kejadian tersebut yang bisa dicegah dan diperkirakan (Babamohamadi, et al., 2016).

\section{METODE}

Metode yang digunakan ialah menggunakan literature review. Metode ini menganalisis, mengeksplorasi dan kajian bebas pada artikel, jurnal, text book, maupun e-book yang relevan dan berfokus pada metode pembelajaran klinik yang mempengaruhi pengetahuan perawat terkait dengan sasaran keselamatan pasien

Literatur review ialah penjelasan tentang teori, temuan, serta bahan penelitian lain yang didapatkan dari bahan acuan untuk dijadikan sebagai acuan kegiatan penelitian untuk menyusun kerangka pemikiran yang jelas dari perumusan masalah yang ingin di teliti. Metode ini memberikan gambaran mengenai bagaimana penerapan sasaran keselamataan pasien dirumah sakit. 
HASIL

Perawat mempunyai pengetahuan tentang sasaran keselamatan pasien di rumah sakit dan perawat mampu menerapkan sasaran keselamatan pasien tersebut. Dari hasil yang dapat diperoleh dari menerapkan sasaran keselamatan tersebut langkah utama yang dilakukan adalah pengetahuan yang dimiliki seorang perawat. Pengetahuan sangatlah penting bagi perawat untuk menerapkan keselamatan pasien di rumah sakit.

Perawat memiliki peranan yang sangat penting dalam mewujudkan keselamatan pasien di rumah sakit yaitu sebagai pemberi pelayanan keperawatan, perawat harus mematuhi semua standar pelayanan dan SOP yang telah dibuat dan ditetapkan oleh rumah sakit serta tidak luput pula dalam menerapkan prinsip-prinsip etik dalam pemberian pelayanan keperawatan kepada pasien.

Memberikan pendidikan kepada pasien dan keluarga tentang asuhan yang diberikan, menerapkan kerjasama tim kesehatan yang handal dalam melakukan penyelesaian masalah terhadap kejadian yang tidak diharapkan, melakukan pendokumentasian dengan benar dari semua asuhan keperawatan yang diberikan kepada pasien dan keluarga serta komunikasi efektif yang merupakan hal yang sangat berperan terhadap keberhasilan suatau pelayanan yang diberikan kepada pasien dan keluarganya.

\section{PEMBAHASAN}

Keselamatan pasien merupakan suatu prosedur atau proses dalam suatu rumah sakit yang memberikan pelayanan kepada pasien yang lebih aman, dimana dipengaruhi oleh pengetahuan dan penerapan dari perawat pelaksana yang mengutamakan kepentingan dan keselamatan pasien. Prosedur keselamatan pasien ini sangat menjamin peningkatan mutu dari suatu rumah sakit. Karena suatu rumah sakit dapat dikatakan memiliki mutu yang baik jika pelayanan untuk keselamatan pasien juga sudah baik dan benar.

Upaya penerapan keselamatan pasien sangatlah tergantung dari pengetahuan perawat. Apabila perawat menerapkan keselamatan pasien yang didasari oleh pengetahuan yang memadai, maka perilaku keselamatan pasien oleh perawat tersebut bersifat berkepanjangan (longlasting). Seorang perawat dalam memberikan asuhan keperawatan kepada pasien harus memiliki pengetahuan yang benar, keterampilan, dan sikap untuk menangani kompleksitas perawatan kesehatan. 
Rumah sakit ialah layanan jasa kesehatan yang memiliki peran penting bagi kehidupan masyarakat. Rumah sakit adalah tempat yang sangat kompleks yang terdapat berbagai macam obat, tes dan prosedur, banyak alat dengan teknologinya, berbagai jenis tenaga profesi dan non profesi yang siap memberikan pelayanan kesehatan kepada pasien selama 24 jam terus menerus. Keberagaman dan kerutinan pelayanan tersebut apabila tidak dikelola dengan baik dapat menimbulkan peluang untuk terjadinya kesalahan pelayanan kesehatan yang dapat berakibat terhadap keselamatan pasien.

Maksud dan tujuan dari sasaran keselamatan pasien ialah untuk mendorong peningkatan spesifik dalam keselamatan pasien. Sasaran ini mengawasi area yang bermasalah dalam pelayanan kesehatan dan menguraikan tentang solusi atas konsensus berbasis bukti dan keahlian terhadap permasalahan ini. Dengan pengakuan ini bahwa desain atau rancangan system yang baik itu intrinsic/menyatu dalam pemberian asuhan keperawatan yang aman dan bermutu tinggi, tujuan sasaran umumnya yaitu difokuskan kepada solusi secara system, bila memungkinkan.

Sasaran juga tersistem, sama halnya dengan standar lain, standar (pernyataan sasaran/goal/statement), maksud dan tujuan, atau elemen penilaian. Sasaran ini diberi skor sama seperti standar lain dengan "memenuhi seluruhnya", "memenuhi sebagian" atau "tidak memenuhi”.

Keselamatan pasien merupakan suatu sistem yang mencegah terjadinya Kejadian Tidak Diharapkan (KTD) akibat tindakan yang dilakukan atau bahkan tidak dilakukan oleh tenaga profesi maupun non profesi. Sistem tersebut meliputi: assessmen resiko, identifikasi dan pengelolaan hal yang berhubungan dengan risiko pasien, pelaporan dan analisis insiden, kemampuan belajar dari insiden dan tindak lanjutnya serta implementasi solusi untuk meminimalkan timbulnya resiko (Depkes, 2008).

Perawat sebagai tenaga kesehatan yang jumlahnya lebih besar di rumah sakit yaitu (sebesar 40-60 \%) memiliki jobdesk yang dituntut untuk selalu menerapkan 6 sasaran keselamatan pasien. Perilaku perawat dalam mendukung penerapan 6 sasaran keselamatan pasien tersebut sangat diutamakan untuk menjamin keselamatan pasien.

Asuhan keperawatan memiliki peran yang sangat penting dalam mencegah kejadian tidak diharapkan (KTD) yang terjadi pada pasien dan lingkungan keperawatan. Jasa perawat dibutuhkan selama 24 jam oleh 
pasien sehingga memiliki waktu kontak paling banyak dibandingkan dengan tenaga kesehatan lain untuk berhubungan atau kontak dengan pasien.

6 sasaran keselamatan pasien:

\section{Ketepatan identifikasi pasien.}

Untuk menghindari terjadinya insiden terkait identifikasi ini, Indonesia menggunakan sasaran keselamatan pasien yang pertama yaitu ketepatan identifikasi pasien. Langkah pendekatan untuk meningkatkan ketelitian identifikasi pasien seperti kebijakan identifikasi pasien, acuan identifikasi pasien yang dijadikan landassan seluruh unit, prosedur identifikasi pasien melalui pemasangan gelang identitas (minimal memiliki dua identitas), prosedur pemasangan dan pelepasan tanda identitas risiko pada pasien yang datang ke rumah sakit, dan prosedur pemasangan dan pelepasan gelang identitas (Kementerian Kesehatan RI, 2015). Peran tenaga kesehatan dalam melakukan identifikasi yang tepat ialah dapat meminimalkan terjadinya insiden. Kesalahan identifikasi dapat dikarenakan oleh tiga hal, yaitu seperti kesalahan dalam pemasangan lebel, kesalahan dari penulisan, dan kesalahan dalam mengkonfirmasi identitas kepada pasien atau keluarga (Anggraeni, Hakim, \& Widjiati, 2014).
2. Peningkatan Komunikasi Yang Efektif

Rumahsakit wajib mengaplikasikan standar keselamatan pasien dan wajib mengoptimalkan pemenuhan keselamatan pasien. Salah satunya ialah peningkatan komunikasi yang efektif. Komunikasi merupakan penyebab pertama masalah keselamatan pasien. Komunikasi yang baik, tepat, akurat, lengkap, jelas, dan yang mampu dipahami oleh pasien akan mengurangi kesalahan dan menghasilkan peningkatan keselamatan pasien. Manojlovich, (2007) menjelaskan bahwa komunikasi dokter dan perawat mempunyai peran penting dalam menentukan derajat kesehatan pasien, dan kualitas dari pelayanan yang diberikan. Semakin baik komunikasi diantara perawat dan dokter semakin baik pula hasil dari perawatan yang diberikan.

\section{Peningkatan Keamanan Obat Yang Perlu Diwaspadai (High- Alert)}

Salah satu tindakan yang mengancam keselamatan pasien ialah kesalahan pemberian obat yang dilakukan oleh perawat. Sebagian besar perawat telah mengaplikasikan keamanan obat 
dan Cairan. Pengaplikasian delapan benar dalam menunjang keselamatan pasien yaitu: benar pasien, benar obat, benar dosis, benar waktu, benar cara atau route pemberian, benar dokumentasi, benar informasi, dan benar pengkajian juga sudah diterapkan. Menurut Kemenkes (2011), obatobatan menjadi bagian dari rencana pengobatan pasien, manajemen rumah sakit harus berperan secara kritis untuk memastikan keselamatan pasien. Nama Obat, rupa dan ucapan mirip (NORUM), yang membingungkan staf pelaksana adalah salah satu penyebab yang paling sering terjadi dalam kesalahan obat (medication error). Oleh karena itu, kekhawatiran terhadap obat-obat yang tingkat bahayanya tinggi harus ditunjukkan dengan menyimpannya di tempat khusus dan tidak di setiap ruangan. Obatobatan lain juga harus dibawah pengawasan apoteker, sehingga kalau ada dosis yang berlebihan dapat disarankan ke dokternya untuk meninjau ulang terapinya.

\section{Kepastian Tepat-Lokasi, Tepat- Prosedur, Tepat-Pasien Operasi}

Menurut Kemenkes (2011), Salah lokasi, salah prosedur, salah pasien operasi ialah sesuatu yang mencemaskan dan sering terjadi di rumah sakit. Kesalahan ini akibat dari komunikasi yang tidak efektif atau tim bedah yang kurang atau tidak melibatkan pasien pada saat penandaan lokasi. Selain itu, ada beberapa faktor yang juga sering terjadi, antara lain: pengkajian pasien yang tidak layak, penelaahan ulang catatan medis tidak adekuat, budaya yang tidak mendukungnya komunikasi antar anggota tim bedah. Berdasarkan hasil penelitian, sebagian besar perawat sudah melakukan upaya untuk meningkatkan ketepatan lokasi, prosedur, dan pasien operasi sebelum dilakukan operasi ke pasien, antara lain ialah melakukan pengecekan terkait identitas pasien, mengecek ketepatan prosedur dan lokasi operasi serta melakukan beberapa prosedur rutin seperti enema sesuai instruksi oleh dokter, menganjurkan pasien untuk berpuasa, sebelum memberi antibiotik melakukan test alergi terlebih dahulu, menyiapkan dan mengecek hasil foto-foto rontgen dan hasil pemeriksaan lainnya. 
5. Pengurangan Risiko Infeksi Terkait Pelayanan Kesehatan

Indonesia mengaplikasikan sasaran keselamatan pasien ke lima yaitu (pengurangan risiko infeksi terkait pelayanan kesehatan) dengan landasan pengembangan kebijakan tentang pencegahan infeksi, pedoman pencegahan infeksi, SPO cuci tangan, rumah sakit melakukan sosialisasi alat bantu yang digunakan untuk pencegahan infeksi (Kementerian Kesehatan RI, 2015). Indikator ini dipakai oleh seluruh rumah sakit di Indonesia berdasarkan dengan ketentuan pedoman nasional keselamatan pasien rumah sakit "patient safety". Risiko infeksi dapat muncul saat aktifitas pengobatan. Risiko ini dapat dicegah dengan manajemen risiko infeksi yang baik dan benar. Edukasi kepada pasien dapat membantu mengurangi risiko infeksi selama pelayanan kesehatan di rumah sakit. Rumah sakit adalah tempat yang rentan terjadi infeksi nosokomial atau infeksi baru selama masa perawatan. Walaupun dapat juga terjadi pada pengunjung, infeksi ini yang paling sering menginfeksi pasien dengan kondisi daya tahan tubuhnya sedang dalam keadaan menurun. Adanya infeksi baru juga kadang-kadang dapat memicu dampak yang lebih fatal pada saat dirawat.

\section{Pengurangan Risiko Pasien Jatuh}

Insiden pasien jatuh pada saat mendapatkan pelayanan baik rawat darurat, rawat jalan dan rawat inap termasuk dalam insiden terkait keselamatan pasien komponen ke enam. Jumlah kasus jatuh cukup berdampak sebagai penyebab cidera bagi pasien rawat inap. Mengingat risiko pasien jatuh sangatlah besar maka sebagai seorang perawat perlu memikirkan berbagai cara untuk mengurangi terjadinya hal tersebut. Hal ini dilakukan bertujuan agar pasien tidak perlu di rawat di rumah sakit lebih lama akibat komplikasi jatuh. Hasil penelitian menunjukkan lebih dari setengah perawat telah mengaplikasikan usaha pencegahan jatuh dengan menaikkan pengaman atau pembatas tempat tidur. Pemasangan pengaman tempat tidur sangatlah penting disediakan terutama pada pasien dengan kesadaran menurun dan gangguan mobilitas. 


\section{PENUTUP}

Keselamatan pasien merupakan suatu prosedur atau proses dalam suatu rumah sakit yang memberikan pelayanan kepada pasien yang lebih aman, dimana dipengaruhi oleh pengetahuan dan penerapan dari perawat pelaksana yang mengutamakan kepentingan dan keselamatan pasien. Keselamatan pasien merupakan suatu prosedur atau proses dalam suatu rumah sakit yang memberikan pelayanan kepada pasien yang lebih aman, dimana dipengaruhi oleh pengetahuan dan penerapan dari perawat pelaksana yang mengutamakan kepentingan dan keselamatan pasien.

Penerapan sasaran keselamatan pasien yaitu: ketepatan identifikasi pasien, peningkatan komunikasi yang efektif, keamanan obat dan cairan, ketepatan lokasiprosedur-pasien operasi, pengurangan risiko infeksi, dan pencegahan jatuh. Pelaksanaan enam sasaran keselamatan pasien yang dilakukan oleh perawat di rumah sakit berada dalam kategori baik. Diharapkan Pihak rumah sakit dapat melengkapi standar prosedur operasional terkait dengan komunikasi efektif saat melaporkan dan menerima instruksi dari dokter, adanya tanda dan label untuk keamanan dari obat, dan peningkatan supervisi agar pelaksanaan pada teknik aseptik menjadi lebih baik.

\section{REFRENSI}

Andayanie, E. Azizah, K. N. (2020). Faktor Yang Berhubungan Dengan Sasaran Penerapan Patient Safety Perawat Ruang Inap RSUD Lamadukelleng 2020. Window of Public Health Journal. 1(2): 148156.

Arrum, D. Dkk. (2015). Pengetahuan Tenaga Kesehatan Dalam Sasaran Keselamatan Pasien Di Rumah Sakit Sumatera Utara. Idea Nursing Journal. 6(2):1-6.

Helsananewa, A. Dkk. Studi Deskriftif Pelaksanaan Sasaran Keselamatan Pasien Sesuai Instruksi Kars Versi 2012 di IGD Rumah Sakit TNI AD Tk IV 02.07.04 Bandar Lampung. Jurnal Ilmu Kesehatan Masyarakat. 8(3):100-108.

Istiningtyas, A. (2016). Hubungan Sumberdaya Dengan Pelaksana Handover Sebagai Sasaran Keselamatan Pasien. Jurnal Kesmadaska. 141-145.

Keles, A. W. Dkk. (2015). Analisis Pelaksanaan Standar Sasaran Keselamatan Pasien di Unit Gawat Darurat RSUD Dr. Sam Ratulangi 
Tondano Sesuai dengan Akreditasi

Rumah Sakit Versi 2012. JIKMU. 5(2):250-259.

Pambudi, Y. D. W. Dkk. (2018). FaktorFaktor Yang Mempengaruhi Perawat Dalam Penerapan 6 Skp (Sasaran Keselamatan Pasien) Pada Akreditasi JCI (Joint Commission International) Di Ruang Rawat Inap Rumah Sakit Panti Waluya Malang. Nursing News. 3(1):729747.

Setiyani, M. D. Dkk. (2016). Implementasi Sasaran Keselamatan Pasien Di Ruang Rawat Inap Rsu Kabupaten Tangerang. JKFT. (2). 59-69.

Simamora, R. H. (2018). Buku ajar keselamatan pasien melalui timbang terima pasien berbasis komunikasi efektif: SBAR. Medan: USUpress.

Sundoro, T. Dkk. (2016). Evaluasi Pelaksanaan Sasaran Keselamatan Pasien Sesuai Akreditasi Rumah Sakit Versi 2012 di Rumah Sakit Khusus Ibu dan Anak PKU Muhammadiyah Kotagede Yogyakarta. Jurnal Medicoeticolegal dan Manajemen Rumah Sakit. 5(1):40-48.
Surahmat, R. (2019). Hubungan Karakteristik Perawat terhadap Pelaksanaan Sasaran Keselamatan Pasien Pasca Akreditasi Rumah Sakit "X" di Kota Palembang Tahun 2018. Jurnal Ilmiah Universitas Batanghari Jambi. 19(1):1-10.

Zahroti, E. N. Chalidyanto, D. (2108). Pendekatan Pdsa Untuk Perbaikan Proses Pada Indikator Sasaran Keselamatan Pasien Di Rumah Sakit. Jurnal Administrasi Kesehatan Indonesia. 6(2):111121.

Zakaria, F. M. (2017). Pengaruh Kualitas Pelayanan Dan Sasaran Keselamatan Pasien Terhadap Kepuasan Pasien Rumah Sakit Prima Husada Malang. JIMMU. 2(2):98-107. 